\title{
Síndrome de Bickerstaff. Caso clínico
}

Bickerstaff syndrome. Case report

\author{
Dra. Ana Paula Arias ${ }^{a}$, Dra. Agustina Santoni ${ }^{a}$ Dra. Belén Goenaga ${ }^{a}$ Dra. María José Martínez ${ }^{a}$ \\ y Dra. Natalia González ${ }^{a}$
}

\begin{abstract}
RESUMEN
El síndrome de Guillain-Barré se define como una polirradiculoneuropatía aguda, de inicio súbito y cuyo origen es, en la mayor parte de los casos, autoinmune. Se manifiesta como un cuadro de parálisis motora fláccida, de tipo ascendente, acompañada de arreflexia, con alteraciones sensitivas o sin ellas. Es la causa más frecuente de parálisis fláccida aguda en niños previamente sanos. Presenta distintas variantes que forman parte de un mismo espectro. Una de ellas es el síndrome de Bickerstaff, caracterizado por ataxia, oftalmoplejía externa asociada a encefalopatía o hiperreflexia.

Es importante el diagnóstico precoz a fin de poder instaurar rápidamente medidas de sostén y tratamiento que beneficiarán a aquellos pacientes que progresan hacia un cuadro de mayor gravedad.

Presentamos el caso de un niño de 4 años de edad, previamente sano, que presenta cuadro compatible con síndrome de Bickerstaff.

Palabras clave: síndromede Guillain-Barré, síndromede Bickerstaff.
\end{abstract}

\begin{abstract}
Guillain-Barré syndrome is defined as an acute polyradiculoneuropathy, with sudden onset and its origin being mostly autoimmune. It is characterized by flaccid paralysis, symmetrical and ascending, together with areflexia, with or without sensory disturbances. It is the primary cause of acute flaccid paralysis in previously healthy children. Guillain-Barré syndrome presents different variants as part of the same spectrum. One of this is the Bickerstaff syndrome, characterized by ataxia, encephalopathy, hyperreflexia and external ophthalmoplegia. Early diagnosis is important with the view to establishing an early treatment that will be beneficial for those patients that progress to a more serious illness. We report the case of a 4-year-old boy who was previously healthy, and then presented symptoms that are compatible with Bickerstaff syndrome.
\end{abstract}

Key words: Guillain-Barré syndrome, Bickerstaffs syndrome.

http:/ /dx.doi.org/10.5546/aap.2015.e226

\section{INTRODUCCIÓN}

El síndrome de Guillain-Barré (SGB) se define como una polirradiculoneuropatía aguda, cuya

a. Hospital de Niños "Dr. Ricardo Gutiérrez". CABA.

Correspondencia:

Dra. Ana Paula Arias: anaparias31@gmail.com

Financiamiento: Ninguno.

Conflicto de intereses: Ninguno que declarar.

Recibido: 8-1-2015

Aprobado: 23-2-2015 etiología es, en la mayor parte de los casos, autoinmune. Se manifiesta como un cuadro de parálisis motora fláccida, ascendente, acompañada de arreflexia, con alteraciones sensitivas o sin ellas. ${ }^{1}$ Constituye la causa más frecuente de parálisis fláccida aguda en niños previamente sanos. ${ }^{2} \mathrm{Su}$ incidencia oscila entre 0,5 y 1,5 casos por 100000 en la población de 0 a 17 años. ${ }^{3}$

El $75 \%$ de los casos está precedido por un proceso infeccioso agudo en las 3 semanas previas.

Las distintas variantes clínicas forman parte de un mismo espectro. Una de estas es el síndrome de Bickerstaff, que se presenta con ataxia, oftalmoplejía externa asociada a encefalopatía o hiperreflexia. ${ }^{4} \mathrm{La}$ inmunoglobulina intravenosa (IgIV) es el tratamiento de elección en los niños.

\section{CASO CLÍNICO}

Paciente de sexo masculino de 4 años de edad, que, desde hace una semana, padece síndrome broncoobstructivo. Consulta por presentar dismetría y ataxia de 48 horas de evolución.

Se lo valora en regular estado general, afebril, sensorio alternante, con rigidez de nuca, pupilas isocóricas reactivas, reflejo fotomotor derecho conservado, izquierdo hiporreactivo. Reflejos osteotendinosos conservados (ROT), debilidad muscular en cuatro miembros, tos inefectiva. Sin compromiso deglutorio. Con diagnóstico presuntivo de mesencefalitis, se decide su internación.

Al momento del ingreso, se realizan los siguientes estudios (Tabla 1): tomografía computada (TC) y resonancia magnética nuclear (RMN) de cerebro con y sin contraste, y electroencefalograma, todo dentro de los límites normales. Se constata leucocitosis con neutrofilia y reactantes de fase aguda aumentados, hiperproteinorraquia y celularidad aumentada en líquido cefalorraquídeo (LCR). Se realiza inmunofluorescencia indirecta de aspirado nasofaríngeo: picornavirus positivo, mycoplasma pneumoniae negativo. Dos hemocultivos y el cultivo de LCR fueron negativos. Se solicitan 
serologías para herpes virus simplex 1-2, varicela zóster, anti antígeno de la cápside de virus Epstein Barr, anticuerpos anti virus de la hepatitis B y C, anticuerpos anti virus de la inmunodeficiencia humana, Ig para Bartonella henselae.

Estudio virológico del LCR (reacción en cadena de la polimerasa para echovirus, enterovirus, virus herpes humano 6 y virus varicela zóster-VZV-). PCR para enterovirus en sangre. Se realizan dos coprocultivos: ausencia de enteropatógenos. Radiografía de tórax: normal. Se desestima etiología toxicológica mediante interrogatorio. Movimientos oculares conservados. Fondo de ojos: normal. Se inicia tratamiento con aciclovir de $30 \mathrm{mg} / \mathrm{kg} /$ día endovenoso, que se suspende tras descartar etiología herpética.

Las primeras $48 \mathrm{~h}$, evoluciona con mejoría del sensorio, progresión de la debilidad muscular a predominio apendicular proximal e hiporreflexia en 4 miembros. Se vuelven a realizar estudios ( $T a-$ bla 2), con nuevo citoquímico de LCR, en el que se observa disociación albúmino-citológica: proteinorraquia (491 mg/dl) y celularidad $(41 / \mathrm{ml}-85 \%$ mononucleares). Bandas oligoclonales en LCR: patrón tipo 1 sin producción local de IgG, IgG en LCR de 48,1 mg/dl, IgG en suero de 1790 mg/ dl. Se solicitaron anticuerpos específicos antigangliósidos en LCR y suero (anti-GM1, anti-GQ1B), los cuales resultaron negativos. RMN de columna con contraste, que informa en T2 leve hiperintensidad en el espesor del cono medular y refuerzo de las raíces ventrales que conforman la cola de caballo, compatible con radiculopatía inflamatoria o desmielinizante.

Por presentar cuadro clínico de debilidad muscular progresiva, ataxia, oftalmoparesia, hiporreflexia asociada a encefalitis, disociación albúmino-citológica en LCR e imágenes compatibles, se presume síndrome de Bickerstaff.

Se indica tratamiento con gammaglobulina a

TABLA 1. Resultados de los estudios solicitados al momento del ingreso

\begin{tabular}{|c|c|}
\hline Estudio & Resultado \\
\hline TC de cerebro con y sin contraste & Normal \\
\hline RMN de cerebro con y sin contraste & Normal \\
\hline Electroencefalograma & Normal \\
\hline Celularidad en LCR & 11 células $/ \mathrm{mm}^{3}$ \\
\hline Eritrosedimentación & $35 \mathrm{~mm} / \mathrm{h}$ \\
\hline Proteína $C$ reactiva & $7,57 \mathrm{mg} / \mathrm{L}$ \\
\hline Proteinorraquia & $42 \mathrm{mg} / \mathrm{dl}$ \\
\hline Hemograma & $\begin{array}{c}\text { Glóbulos blancos } 11600 / \mathrm{mm}^{3} \\
\text { (neutrófilos: 70\%; linfocitos: } 23 \% \text { ) }\end{array}$ \\
\hline Inmunofluorescencia indirecta de aspirado nasofaríngeo & $\begin{array}{c}\text { Picornavirus positivo, } \\
\text { mycoplasma pneumoniae negativo }\end{array}$ \\
\hline Hemocultivos por 2 & Negativos \\
\hline Cultivo de LCR & Negativo \\
\hline Ig G y M para herpes virus simplex 1, 2 & Negativo \\
\hline Ig G para varicela zóster & Negativo \\
\hline Ig G y M para el antígeno de la cápside de virus Epstein Barr & Negativo \\
\hline Anticuerpos anti core del virus de la hepatitis B & Negativo \\
\hline Anticuerpo anti VIH 1 y 2 & No reactivo \\
\hline Anticuerpo anti virus de la hepatitis C & No reactivo \\
\hline Ig G y M para Bartonella henselae & Negativo \\
\hline PCR en LCR para echovirus, enterovirus, varicela zóster y herpes humano tipo 6 & Negativos \\
\hline PCR en sangre para enterovirus & Negativo \\
\hline Coprocultivo por 2 & Ausencia de enteropatógenos \\
\hline Radiografía de tórax frente & Normal \\
\hline Fondo de ojos & Normal \\
\hline
\end{tabular}

TC: tomografía computada; RMN: resonancia magnética nuclear; LCR: líquido cefalorraquídeo;

PCR: proteína C reactiva; VIH: virus de la inmunodeficiencia humana. 
$2 \mathrm{~g} / \mathrm{kg} /$ dosis en 5 días y se constata, durante el pasaje, notoria mejoría de la debilidad muscular, recuperación total de ROT y recuperación progresiva de la marcha. Inicia kinesioterapia motora.

A la cuarta semana de inicio del cuadro, se realiza estudio neurofisiológico. Electromiograma de miembros inferiores (MM. II.): normal; de miembros superiores (MM. SS.): patrón neurogénico crónico. Velocidad de conducción sensitiva nerviosa: leve polineuropatía axonal motora en miembros superiores. Ausencia de ondas F en MM. SS. Nervios motores, sensitivos y ondas F de MM. II.: normales.

El seguimiento del paciente fue irregular y en diferentes centros, por lo que no se cuenta con información sobre la evolución posterior.

\section{DISCUSIÓN}

El síndrome de Bickerstaff (SB) es una de las variantes del SGB que se caracteriza por la asociación de ataxia y oftalmoplejía acompañada de alteración de la conciencia e hiperreflexia. La disminución o ausencia de ROT está presente en el 58\% de los casos. La asociación con tetraparesia fláccida simétrica se observa en el $60 \%$ de los SB. ${ }^{5}$

Aproximadamente, dos tercios de los casos de SGB presentan el antecedente de un cuadro infeccioso respiratorio o gastrointestinal. ${ }^{2}$ En un estudio de reporte de 62 casos de SB, se encontró antecedente de enfermedad infecciosa en $92 \%$ de los casos; el $66 \%$ fue una infección respiratoria. ${ }^{5}$ La relación con el desencadenante infeccioso radica en la similitud antigénica entre ciertos componentes de estos gérmenes y gangliósidos del sistema nervioso. Es bien conocida la asociación del SGB con la infección por Campylobacter jejuni, principalmente, las variantes síndrome de Miller Fisher (SMF), y con la neuropatía axonal motora aguda (AMAN). ${ }^{3}$
El SB presentó una asociación del 23\% con este germen. ${ }^{5}$ Tanto en el SB (68\%) como en el SMF (82\%), predominan los autoanticuerpos en contra del gangliósido GQ1b ${ }^{6}$ cuya principal localización es en los núcleos oculomotor, troclear y abducens y en los husos musculares, lo que se correlaciona con la clínica de estas dos patologías, que comparten la ataxia y la oftalmoplejía y difieren en el compromiso de sensorio característico del SB. En nuestro caso, dichos anticuerpos resultaron negativos.

Respecto al diagnóstico, los estudios electrofisiológicos son los más específicos y sensibles. Las alteraciones en dichos estudios suelen aparecer tras 2-3 semanas del inicio del cuadro y demuestran un patrón característico, de acuerdo con el subtipo de SGB, desmielinizante o axonal. El patrón predominante en el SB es el axonal. ${ }^{5}$

En cuanto al LCR, no solo ayuda a descartar otros diagnósticos diferenciales, sino que también el hallazgo de disociación albuminocitológica, tal como ocurrió en nuestro paciente, apoya el diagnóstico presuntivo. En el SB, dicho hallazgo se encuentra en el 19\% de los pacientes durante la primera semana posterior al comienzo de la sintomatología, mientras que, en la tercera semana, el porcentaje asciende al $75 \%{ }^{5}$

Respecto al rol de los estudios por imágenes, la RMN con gadolinio tiene una sensibilidad mayor del $90 \%$. Los hallazgos compatibles incluyen hiperintensidad en las raíces ventrales que conforman la cauda equina. No obstante, la especificidad es menor, ya que otras entidades, como ciertas metabolopatías, producen alteraciones similares. ${ }^{2}$ Un $30 \%$ de los casos de SB presentan alteraciones en la RMN, cuyas localizaciones más frecuentes son el tronco encefálico, tálamo, cerebelo y sustancia blanca del cerebro. ${ }^{5}$

Tabla 2. Resultados de los estudios solicitados luego de $48 \mathrm{~h}$

\begin{tabular}{lc}
\hline Estudio & Resultado \\
\hline Citoquímico de LCR & Disociación albúmino-citológica \\
Bandas oligoclonales en LCR & Patrón tipo 1 sin producción local de IgG \\
IgG en LCR & $48,1 \mathrm{mg} / \mathrm{dl}$ \\
IgG en suero & $1790 \mathrm{mg} / \mathrm{dl}$ \\
Anticuerpos específicos antigangliósidos & \\
en suero (anti-GM1, anti-GQ1B) & LCR y negativos \\
RMN de columna con contraste & Leve hiperintensidad en el espesor del cono medular \\
& y refuerzo de las raíces ventrales que conforman la cola de caballo \\
\hline
\end{tabular}

RMN: resonancia magnética nuclear; LCR: líquido cefalorraquídeo. 
En cuanto a los diagnósticos diferenciales del $\mathrm{SB}$, la patología infecciosa adquiere importancia por la encefalopatía que lo caracteriza.

Todo paciente pediátrico que presente este cuadro debe ser hospitalizado a fin de realizar un monitoreo cercano de las funciones motora, autonómica y respiratoria.

El tratamiento de elección de cualquiera de las variantes del SGB consiste en gammaglobulina endovenosa de $2 \mathrm{~g} / \mathrm{kg}$ (como dosis total). ${ }^{7,8}$ Dicho tratamiento se asocia a una reducción del tiempo hasta la recuperación.

Otra opción terapéutica disponible es la plasmaféresis, ${ }^{9}$ que se suele reservar para pacientes que presentan debilidad muscular rápidamente progresiva, empeoramiento de la función respiratoria, debilidad bulbar significativa, ataxia grave, mala respuesta al tratamiento con gammaglobulina o los que presentaron reacciones adversas con esta.

La mayoría de los casos de SB tienen un curso monofásico y el $66 \%$ presenta remisión completa de los síntomas a los 6 meses del inicio del cuadro. ${ }^{4}$

Finalmente, en cuanto a la mortalidad, oscila entre el 3 y el $4 \%$ y, generalmente, es secundaria a insuficiencia respiratoria o a complicaciones cardíacas.

\section{CONCLUSIONES}

El síndrome de Bickerstaff es una variante poco frecuente del síndrome de Guillain-Barré. Es importante la sospecha ante un cuadro de encefalitis asociada a debilidad muscular y alteración de los ROT, ya que el tratamiento oportuno se asocia a un mejor pronóstico. La sospecha clínica se respalda en alteraciones características en el LCR, neuroimágenes, estudios electrofisiológicos y anticuerpos específicos. El tratamiento de elección es la gammaglobulina.

\section{REFERENCIAS}

1. RyanMM.Guillain-Barrésyndromein childhood.JPaediatr Child Health 2005;41(5-6):237-41.

2. Jones HR Jr. Guillain-Barré syndrome: perspectives with infants and children. Semin Pediatr Neurol 2000;7(2):91-102.

3. Torricelli RE. Síndrome de Guillain Barré en pediatría. Medicina (B. Aires) 2009;69(1 Supl 1):84-91.

4. Overell JR, Hsieh ST, Odaka M, Yuki N, Willison H. Treatment for Fisher syndrome, Bickerstaff's brainstem encephalitis and related disorders. Cochrane Database Syst Rev 2007;(1):CD004761.

5. Odaka M, Yuki N, Yamada M, Koga M, et al. Bickerstaff's brainstem encephalitis: clinical features of 62 cases and a subgroup associated with Guillan-Barré syndrome. Brain 2003;126(Pt 10):2279-90.

6. Shahrizaila N, Yuki N. Bickerstaff brainstem encephalitis and Fisher syndrome: anti-GQ1b antibody syndrome. $J$ Neurol Neurosurg Psychiatry 2013;84(5):576-83.

7. Yuki N, Hartung H P. Guillain-Barré syndrome. N Engl J Med 2012;366(24):2294-304.

8. Rosen BA. Guillain-Barré Syndrome. Pediatr Rev 2012;33(4):164-70.

9. Van Doorn PA, Ruts L, Jacobs BC. Clinical features, pathogenesis, and treatment of Guillain-Barré syndrome. Lancet Neurol 2008;7(10):939-50. 